\title{
BMJ Open Resuscitative endovascular balloon occlusion of the aorta (REBOA) in non- traumatic out-of-hospital cardiac arrest: evaluation of an educational programme
}

\author{
Jostein Rødseth Brede, ${ }^{\oplus, 2,3}$ Thomas Lafrenz, ${ }^{4}$ Andreas J Krüger, ${ }^{1,2,3}$ \\ Edmund Søvik, ${ }^{5}$ Torjus Steffensen, ${ }^{6}$ Carlo Kriesi, ${ }^{6}$ Martin Steinert, ${ }^{6}$ Pål Klepstad ${ }^{3,7}$
}

To cite: Brede JR, Lafrenz T, Krüger AJ, et al. Resuscitative endovascular balloon occlusion of the aorta (REBOA) in non-traumatic out-of-hospital cardiac arrest: evaluation of an educational programme. BMJ Open 2019;9:e027980. doi:10.1136/ bmjopen-2018-027980

- Prepublication history and additional material for this paper are available online. To view these files, please visit the journal online (http://dx.doi org/10.1136/bmjopen-2018027980).

Received 16 November 2018 Revised 2 April 2019 Accepted 3 April 2019
D) Check for updates

(c) Author(s) (or their employer(s)) 2019. Re-use permitted under CC BY-NC. No commercial re-use. See rights and permissions. Published by BMJ.

For numbered affiliations see end of article.

\section{Correspondence to} Dr. Jostein Rødseth Brede; jostein.brede@ norskluftambulanse.no

\section{ABSTRACT}

Background Out-of-hospital cardiac arrest (OHCA) is a critical incident with a high mortality rate. Augmentation of the circulation during cardiopulmonary resuscitation (CPR) might be beneficial. Use of resuscitative endovascular balloon occlusion of the aorta (REBOA) redistribute cardiac output to the organs proximal to the occlusion. Preclinical data support that patients in non-traumatic cardiac arrest might benefit from REBOA in the thoracic level during CPR. This study describes a training programme to implement the REBOA procedure to a prehospital working team, in preparation to a planned clinical study.

Methods We developed a team-based REBOA training programme involving the physicians and paramedics working on the National Air Ambulance helicopter base in Trondheim, Norway. The programme consists of a fourstep approach to educate, train and implement the REBOA procedure in a simulated prehospital setting. An objective structured assessment of prehospital REBOA application scoring chart and a special designed simulation mannequin was made for this study.

Results Seven physicians and 3 paramedics participated. The time needed to perform the REBOA procedure was $8.5(6.3-12.7) \mathrm{min}$. The corresponding time from arrival at scene to balloon inflation was $12.0(8.8-15) \mathrm{min}$. The total objective assessment scores of the candidates' competency was 41.8 (39-43.5) points out of 48 . The advanced cardiovascular life support (ACLS) remained at standard quality, regardless of the simultaneous REBOA procedure.

Conclusion This four-step approach to educate, train and implement the REBOA procedure to a prehospital working team ensures adequate competence in a simulated OHCA setting. The use of a structured training programme and objective assessment of skills is recommended before utilising the procedure in a clinical setting. In a simulated setting, the procedure does not add significant time to the prehospital resuscitation time nor does the procedure interfere with the quality of the ACLS.

Trial registration number NCT03534011.

\section{BACKGROUND}

Out-of-hospital cardiac arrest (OHCA) is a critical incident with a high mortality rate. ${ }^{1}$ For non-traumatic cardiac arrest (CA) the
Strengths and limitations of this study

- This study provides insight on the novel use of resuscitative endovascular balloon occlusion of the aorta (REBOA) on out-of-hospital cardiac arrest patients

- It is the first study to describe an extensive educational programme for implementing this procedure.

- It presents a new objective scoring chart for the REBOA procedure.

- It is a single-centre study on anesthesiologists, limiting the generalisability of the data.

- Although it is most relevant for physician manned prehospital services, it is also informative for treatment of in-hospital cardiac arrest.

most frequent aetiology is cardiac disease, ${ }^{23}$ with deaths related to failure to achieve return of spontaneous circulation (ROSC), circulatory failure after ROSC or anoxic brain damage. ${ }^{4}$ During cardiopulmonary resuscitation (CPR), the cardiac output is usually not sufficient to maintain consciousness and the lack of oxygen delivery can result in irreversible damage to vital organs. ${ }^{1}$ Augmentation of the circulation and hence oxygen delivery to vital organs such as the brain and heart during CPR is therefore beneficial.

Balloon occlusion of the aorta was introduced in the Korean War in 1954 as a means to stabilise soldiers with intraabdominal haemorrhages. ${ }^{5}$ After this, resuscitative endovascular balloon occlusion of the aorta (REBOA) has been employed in patients in haemorrhagic shock or CA secondary to trauma. Continuous occlusion of the aorta with REBOA gives a redistribution of cardiac output to the organs proximal to the occlusion including the brain and heart ${ }^{6}$ (figure 1 ).

Several animal studies demonstrate that REBOA during CPR increase both coronary artery blood flow and coronary perfusion 


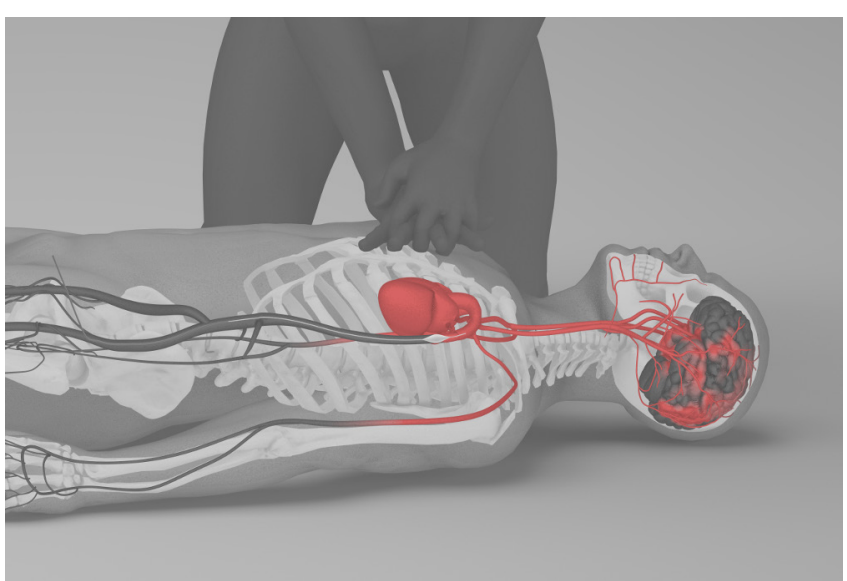

Figure 1 Aortic zone I occlusion.

pressure and increase the rates of ROSC. ${ }^{7-14}$ Aortic occlusion during CPR also gives clinically relevant increased carotid artery blood flow, ${ }^{10}{ }^{15}$ cerebral arterial blood flow ${ }^{8915-17}$ and cerebral perfusion pressure. ${ }^{81518}$ Based on these preclinical data, patients in non-traumatic CA might benefit from REBOA in the thoracic level during CPR.

There are no systematic human studies on the use of REBOA for non-traumatic CA. To our knowledge, only three case reports are published, of which two patients were considered to have a positive effect of REBOA. ${ }^{19-21}$ One explanation for that REBOA is not introduced for OHCA is the feasibility of REBOA insertion in the prehospital setting. However, technological advances in the REBOA technique now allows for fluoroscopy-free aortic occlusion $^{22}$ and REBOA is at present used by numerous prehospital services, both civilian and military on trauma patients. $^{23}$

The Norwegian physician staffed prehospital emergency medical services (P-EMS) include anaesthesiologists. ${ }^{24}$ These physicians will regularly be part of the resuscitation team at OHCA. All anaesthesiologists are skilled in establishing central vascular lines using the Seldinger technique and the use of ultrasound. However, the implementation of a new procedure such as REBOA requires special training before implemented in clinical practice. An educational programme was therefore designed to educate, train and implement the REBOA technique to prehospital personnel. In this report, we describe the organisation of a team-based REBOA training programme and the evaluation of REBOA competencies in a high-fidelity simulation scenario, in preparation for a clinical feasibility study on REBOA in OHCA.

\section{METHODS}

\section{Patients and public involvement}

No patients or public were involved in this study.

\section{Participants}

The physicians and paramedics involved in this study work at the P-EMS base in Trondheim, Norway. The P-EMS has a catchment population of about 700000 and usually transfer patients with OHCA to one tertiary university hospital (St. Olavs Hospital). The service dispose both a helicopter and a rapid response car. All physicians are board certified qualified anesthesiologist with prehospital work experience from 4 to 18 years. The paramedics have from 11 to 34 years work experience in the service. Seven physicians and three paramedics participated.

\section{REBOA procedure}

Aortic zones are divided in three zones, I, II and III, spanning from proximal to distal. Zone I is the descending thoracic aorta between the origin of the left subclavian and celiac arteries. REBOA during CA is placed in zone I, for optimal haemodynamic effect. ${ }^{25}$ The insertion technique of REBOA is based on identification of the femoral artery by ultrasound, insertion of the REBOA catheter over a guidewire and placement based on length of catheter from the insertion $(50 \mathrm{~cm}$ in all patients). The balloon is deflated when the team recognise ROSC. It is reported that guidewire-free platforms can reduce procedure time. ${ }^{26}$ The REBOA Medical catheter use a guidewire for insertion of the balloon catheter and was chosen as this is the catheter currently marketed in Norway and is in use at our hospital. A detailed outline of the procedure is described in online supplementary appendix 1 .

\section{Educational programme}

The educational programme is performed in defined steps and is a combined theoretical and practical training programme. It is based on validated educational models for skill training of other procedures performed by physicians from a variety of specialties. ${ }^{27-29}$ The educational programme is divided in a theoretical part, basic skill training, training in the interventional radiology department and high-fidelity simulation.

\section{Part 1: theoretical part}

The didactic theoretical part of this study is an introduction to the concept of REBOA, as well as placement technique and the necessary equipment, given to both physicians and paramedics. The educational content of this part is a Microsoft PowerPoint presentation and a question-and-answer discussion.

\section{Part 2: basic skill training}

The physicians and paramedics trained repeatedly on a simulation mannequin. This mannequin was designed specifically for this use, in collaboration with engineers at Norwegian University of Science and Technology. The cannulation site is a block made of a mixture of hydrocarbon gel and silicone rubber, measuring $10 \times 20 \times 6 \mathrm{~cm}$. Two compressible silicone rubber tubes (inner diameter 7 and $12 \mathrm{~mm}$ ), representing the femoral artery and vein, was moulded into the block at a depth of $\sim 10 \mathrm{~mm}$. The cannulation site was developed with the capacity of both being replaceable and to withstand several cannulations without leakage or deterioration of the ultrasound image quality. The arterial lumen was of $1 \mathrm{~m}$ length and expanded 
to $3 \mathrm{~cm}$ in diameter, allowing placement of the introducer (Super Arrow-Flex, Teleflex, $7 \mathrm{Fr}, 45 \mathrm{~cm}$ length), guidewire and balloon catheter (REBOA Medical, $7 \mathrm{Fr}, 20 \mathrm{~mm}$ diameter, $30 \mathrm{~mm}$ occlusion length). The arterial tubing was not designed to give a realistic tactile feedback. This training ensured knowledge of the equipment, correct technique and correct placement of the REBOA catheter. It also allowed the trainees to repeat the procedure as many times as necessary to obtain the proper skill and confidence in performing the procedure. The training was observed by the first author, available for questions and/or guidance.

\section{Part 3: interventional radiology department}

The physicians attended 1 day at the interventional laboratory, St. Olavs Hospital. Similar guidewires, introducers and catheters as used in REBOA are in daily use at this laboratory. The physician participated in inserting the equipment in patients scheduled for angiography under guidance and supervision of an experienced interventional radiologist. Vascular access was achieved using ultrasound guidance. After training, each operator was approved for the REBOA procedure by a consultant interventional radiologist.

\section{Part 4: high-fidelity simulation}

This part was held in the Centre for Medical Simulation, St. Olavs Hospital. The facility simulated a prehospital setting and was equipped with sound recording and video recording and a one-way mirror window. Video sequences were used in the debriefing session.

The scenario started with establishing advanced cardiovascular life support (ACLS) according to current guidelines from The Norwegian Resuscitation Council. ${ }^{30}$ Ambulance personnel and/or medical students trained in ACLS participated, which is representative of the personnel resources usually available at scene. After endotracheal intubation, establishing manual chest compression and intravenous access on the upper body, the decision to insert a REBOA catheter was made. The resuscitation mannequin used (Resusci Anne First Aid, Laerdal Medical, Norway) is not designed for use of a mechanically chest compression machine; therefore, only manual chest compressions were performed (figure 2). The ultrasound-guided femoral artery access was performed on the designed cannulation block, integrated into the resuscitation mannequin.

All teams where given the same case; a 59-year-old man with known hypertension, monotherapy antihypertensive treatment, suffering from a CA at his home, wife present and by-stander CPR of good quality until the ambulance crew arrived. Initial rhythm was ventricular fibrillation (VF) and this VF was refractory regardless of other treatment than REBOA. ROSC was simulated $1 \mathrm{~min}$ after balloon occlusion. The scenario was aborted after the team recognised ROSC and started to prepare for departure to hospital.

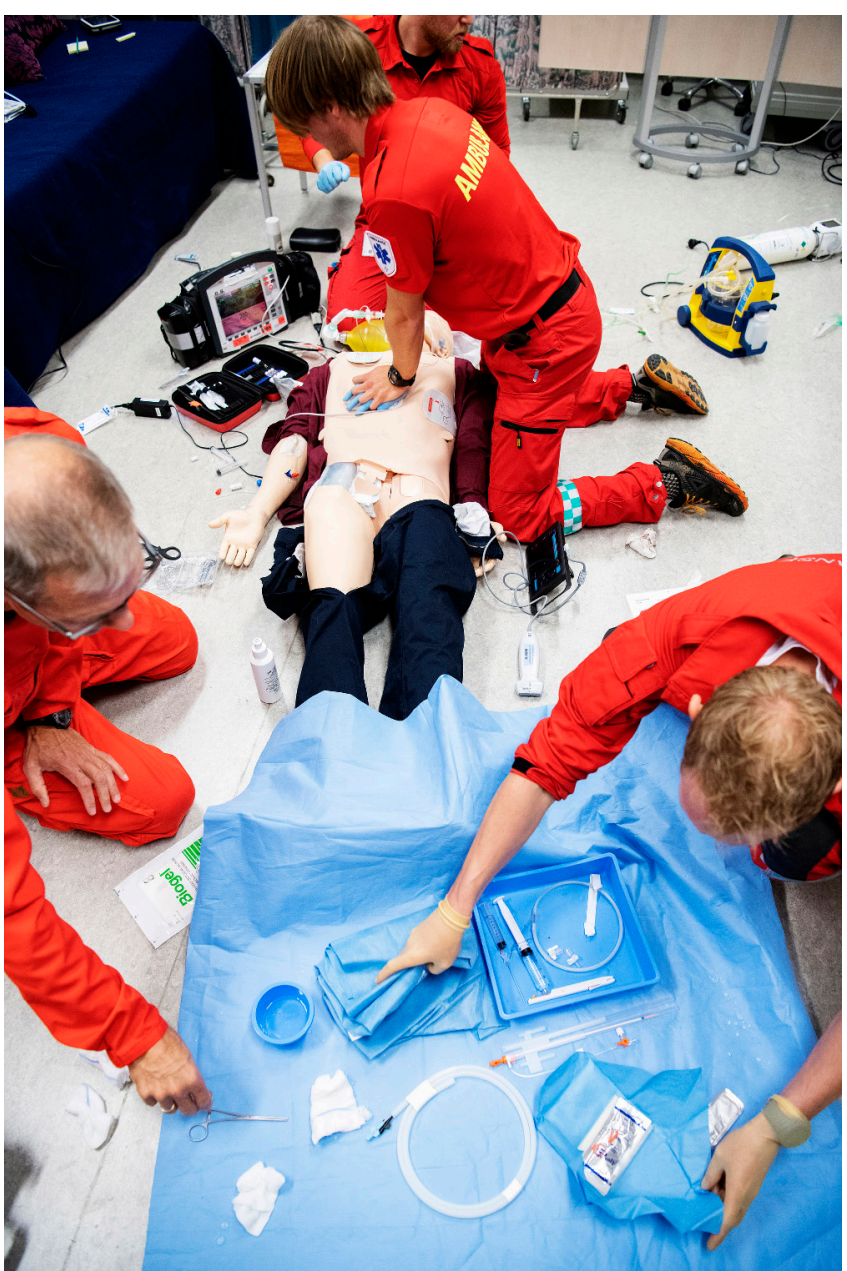

Figure 2 High-fidelity simulation with REBOA application during ACLS. ACLS, advanced cardiovascular life support; REBOA, resuscitative endovascular balloon occlusion of the aorta.

\section{Assessment of performance}

Global rating scale (GRS) is an assessment tool based on different aspect of quality in operative performance, adapted from a validated scoring system. ${ }^{31}$ It is a quantitative marker of performance and is not specific to the REBOA procedure and may apply to other endovascular or technical procedures. It is shown that procedure-specific rating scales can be used to assess trainee's competence in endovascular procedures ${ }^{32}$ or other bedside procedures. ${ }^{27}$ Since a GRS for a prehospital REBOA procedure does not exist, an objective structured assessment of prehospital REBOA application (OSAPRA) chart, modified for the REBOA procedure, was developed (figure 3). The OSAPRA consist of 12 5-point categorical scores each anchored $0-4$. Cut scores for adequate performance had to be determined without previous empirical data. Based on what was considered as the minimum level of performance, the investigators agreed on a cut score of 30 of a total of 48 points on the OSAPRA. Each assessment was performed based on video recording and done independently by two observers. If major discrepancies between the observer ratings occurred, a third 
Trainee:

Evaluator:

Indication for REBOA

Obtains relevant medical history

0 : Does not obtain any information

and physiological values

2: Obtains sufficient information, partial completion of checklist

4: Obtains relevant information and completes checklist

Preparations for the procedure

\begin{tabular}{|l|l|l|}
\hline \multirow{3}{*}{ Informs crew about the decision } & 0: Does not inform crew at all & \\
\cline { 2 - 3 } & 2: Gives sufficient information & \\
\cline { 2 - 3 } & 4: Informs in a relevant and precise way & \\
\hline
\end{tabular}

\begin{tabular}{|l|l|l|}
\hline \multirow{3}{*}{ Prepares the patient } & 0: Does not prepare patient for the procedure at all & \\
\cline { 2 - 3 } & 2: Prepares the patient sufficiently & \\
\cline { 2 - 3 } & $\begin{array}{l}\text { 4: Prepares the patient with desinfectant, sterile cloth } \\
\text { and uses ultrasound probe cover }\end{array}$ & \\
\hline
\end{tabular}

Performing the procedure

\begin{tabular}{|l|l|l|}
\hline \multirow{3}{*}{ Proficiency in ultrasound imaging } & 0: Shows no skill in identifying vessels and structures & \\
\cline { 2 - 3 } & 2: Shows adequate skills in identifying vessels and structures & \\
\cline { 2 - 3 } & 4: Shows ample skills in identifying vessels and structures & \\
\hline
\end{tabular}

\begin{tabular}{|l|l|l|}
\hline \multirow{3}{*}{ Intraarterial cannulation } & 0: Does not use needle-tip-tracking to cannulate & \\
\cline { 2 - 3 } & 2: Uses some needle-tip-tracking & \\
\cline { 2 - 3 } & 4: Display ample skills in needle-tip-tracking and cannulation & \\
\hline
\end{tabular}

\begin{tabular}{|l|l|l|}
\hline \multirow{4}{*}{ Inserting guidewire } & $\begin{array}{l}\text { 0: Does not stabilize and angle the needle when inserting wire } \\
\text { and does no measurement of guidewire length }\end{array}$ & \\
\cline { 2 - 3 } & $\begin{array}{l}\text { 2: Handles the needle suficiently when inserting the wire and } \\
\text { handles guidewire somewhat skilled }\end{array}$ & \\
\cline { 2 - 3 } & $\begin{array}{l}\text { 4: Handles the needle proficiently when inserting the wire } \\
\text { and uses correct insertion length with impecable handling of wire }\end{array}$ & \\
\hline
\end{tabular}

\begin{tabular}{|l|l|l|}
\hline \multirow{2}{*}{ Inserting introducer } & 0: Does not make skin incision and handles the introducer poorly & \\
\hline & 2: Makes skin incision and handles the introducer sufficiently & \\
\cline { 2 - 3 } & 4: Makes skin incision and handles the introducer proficiently & \\
\hline
\end{tabular}

\begin{tabular}{|l|l|l|}
\hline \multirow{3}{*}{ Inserting the REBOA } & 0: Poor handling of catheter & \\
\cline { 2 - 3 } & 2: Sufficient handling of the catheter and placementh of length & \\
\cline { 2 - 3 } & 4: Shows ample skills in handling catheter and correct length & \\
\hline
\end{tabular}

\begin{tabular}{|l|l|l|}
\hline \multirow{2}{*}{ Fixation } & 0: No fixation of catheter & \\
\cline { 2 - 3 } & 2: Fixation with dressing/tape or suture & \\
\cline { 2 - 3 } & 4: Fixation with dressing/tape and suture & \\
\hline
\end{tabular}

\section{After ROSC}

\begin{tabular}{|l|l|l|}
\hline \multirow{2}{*}{ Deflation of the balloon } & 0: Does not deflate the balloon at all & \\
\cline { 2 - 3 } & 2: Deflates the balloon appropriately when achieved ROSC & \\
\cline { 2 - 3 } & 4: Deflates the balloon with perfect timing at ROSC & \\
\hline
\end{tabular}

Coorporation with assistant
\begin{tabular}{|l|l|l|}
\hline \multirow{3}{*}{ Communication } & 0: Does not communicate with the assistant at all & \\
\hline & 2: Communicates sufficiently with the assistant & \\
\hline & 4: Communicates in a clear and proficient way & \\
\hline \multirow{3}{*}{ Use of assistant } & 0: Does not make use of assistant at all & \\
\hline & 2: Uses assistant in a sufficient way & \\
\hline & 4: Uses assistant proficiently and optimally & \\
\hline
\end{tabular}

Total score:

of total $48 \overline{\overline{ }}$

Time

Time spent from start REBOA procedure to occlusion of aorta

Figure 3 Objective structured assessment of prehospital REBOA application chart. REBOA, resuscitative endovascular balloon occlusion of the aorta; ROSC, return of spontaneous circulation. 
observer performed an independently assessment, then the observers discussed until agreement.

\section{Debriefing}

After every session, a semistructured debriefing was held, led by the two observers. The use of debriefing after a simulation event is an important tool for learning ${ }^{33}$ and can be used to develop and implement a new procedure. ${ }^{34}$ All members of the resuscitation team participated in this open discussion. The debriefers ensured that following questions were answered: was the physician able to maintain in control of the resuscitation? Did the patient receive standard care? Did the procedure interfere with the resuscitation? Did the resuscitation interfere with the procedure? Did the two teams, ambulance crew and P-EMS crew, cooperate well? Was this training programme feasible for implementing this new procedure?

\section{Statistics}

All data are descriptive and given as absolute numbers. Due to the descriptive nature of the study, no formal sample testing was performed.

\section{RESULTS}

\section{Completion of the training programme}

The theoretical education and mannequin training were completed within 2 days, with half of the crew (physicians and paramedics) present each day. This ensured a common understanding of the theoretical background and purpose of the intervention, as well as building a consensus on logistics and work pattern. In addition to this training session, a mannequin was installed at the helicopter base, enabling the crew to practice the procedure.

The cannulation block made for training was well appraised. The tactile feedback, needle puncturing and inserting of guidewire, introducer and balloon sheaths was of life-like quality. The ultrasound quality was also adequate, hence reflecting a realistic situation. Each training block tolerated $>20$ punctures.

The patient cannulation in the radiological department was completed over a period of 3 weeks. All seven physicians were approved for competency by the consulting interventional radiologist.

The high-fidelity simulations were completed over a period of 4 days, with one or two physicians participating each day. One of the paramedics attended 2 days.

\section{Time for REBOA procedure at simulation}

The time needed to perform the REBOA procedure was 8.5 (6.3-12.7, SD 2.2) min (figure 4). The time interval started when the physician called procedural start and stopped when the balloon was inflated. The corresponding time from arrival at scene to balloon inflation was $12.0(8.8-15$, SD 2.1) $\mathrm{min}$.

\section{Competency assessment of REBOA procedure in simulation}

The total objective assessment scores of the candidates' competency was 41.8 (39-43.5, SD 1.4) points out of 48 (figure 5). All scores are mean values from the two observers. No major discrepancies in grading of the candidates occurred between the observers.

\section{Debriefing after simulation}

All resuscitation teams regarded the ACLS to be of standard quality. None of the teams felt that neither the REBOA procedure nor the ACLS interfered with each other negatively. The team leaders (physicians) all considered themselves to 'be on top of the situation', even though they concentrated on performing a new specialised procedure. Another factor that were emphasised is that the paramedics are not used to sterile procedures and in this specific procedure they have a crucial role in handling equipment to the physicians. The participants considered this four-step training to implement the

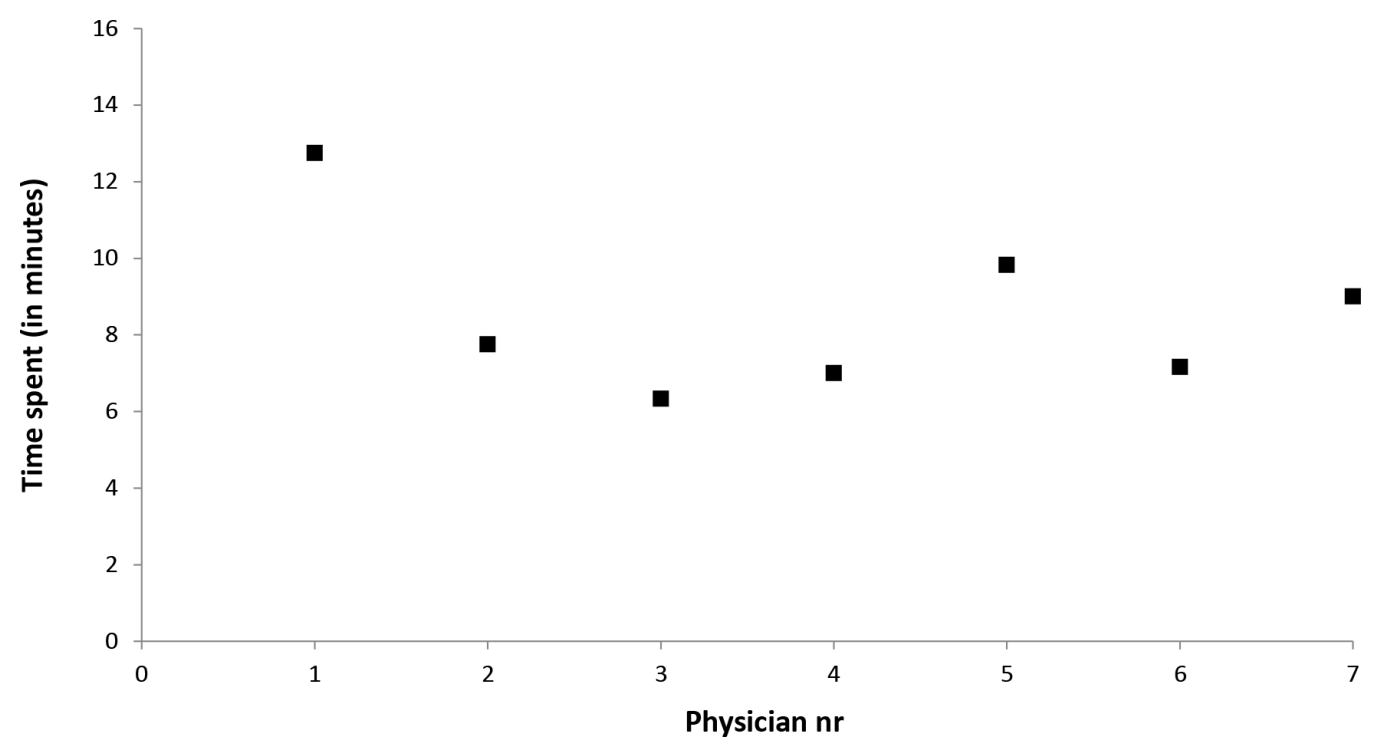

Figure 4 Time (minutes) used to perform the procedure for the seven candidates. 


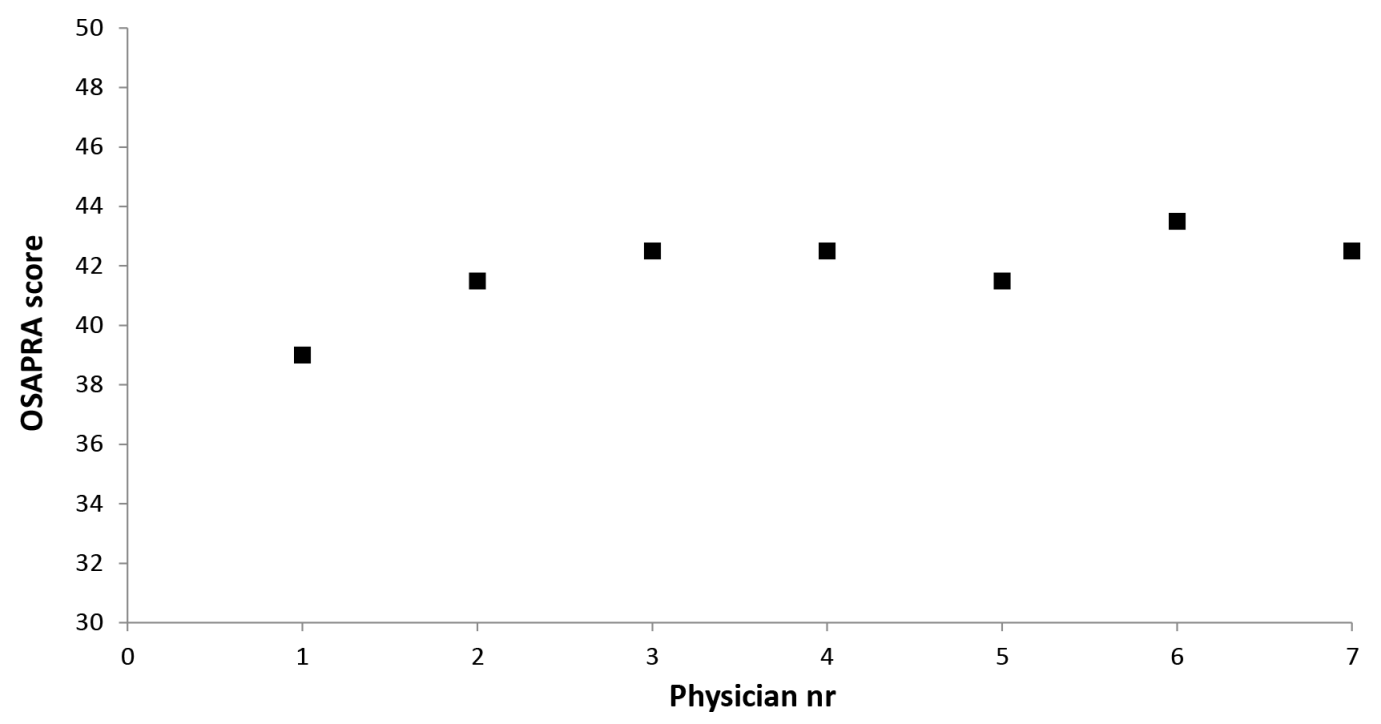

Figure 5 OSAPRA scores for the seven candidates. OSAPRA, objective structured assessment of prehospital REBOA applica+tion.

REBOA technique to be adequate and recommended before use in a clinical setting.

\section{DISCUSSION}

This study showed that a team based four-step educational programme resulted in adequate performance of a REBOA procedure in a simulated OHCA setting.

This educational programme's stepwise combination of theory, training on mannequins and patients and the use of high-fidelity simulation provides the trainees with adequate competency in a simulated model. The time needed to establish a REBOA catheter was $\sim 8.5 \mathrm{~min}$. Based on the feedback from the participants and the observers, we observed that the procedure did not interfere with the quality of the ACLS given simultaneously. This indicates that the procedure does not add significant time to the prehospital resuscitation time and will not interact negatively on established care.

The use of ultrasound is mandatory. A landmark-oriented approach to femoral arterial cannulation is difficult in patients with low blood pressure or no palpable femoral pulse, which is the case in $40 \%$ of patients receiving CPR. ${ }^{35}$ Ultrasound guidance for femoral artery catheterisation is associated with $49 \%$ reduction in overall complications and increases the likelihood of first-attempt success. ${ }^{36}$ Several studies describes how to measure or predict the length from the common femoral arterial puncture site to zone I. ${ }^{37-39}$ Detailed calculations, regardless of simple input parameters, are not likely to be performed in a prehospital setting. Based on the experiences from the catheterisation lab at St. Olavs Hospital, we used a fixed length of guidewire and balloon catheter placement. The placement was also controlled with a present pulse in the left radial artery suggesting balloon inflation below the left subclavian artery. The descending aorta is $\sim 25 \mathrm{~mm}$ in width in the age span of patients eligible for inclusion. ${ }^{40}{ }^{41}$ To minimise the risk of complications such as aortic rupture ${ }^{22}$ or local complications, 7 Fr equipment and a $20 \mathrm{~mm}$ balloon is used. Hence, some patients will potentially have subtotal aortic occlusion. Given an occlusion length of $30 \mathrm{~mm}$, the great increase in resistance to blood flow will provide the same haemodynamic effect and limit the risk of aortic injury. Thus, for REBOA done in the prehospital setting, there must be a consideration for partial aortic occlusions versus to avoid risk of aortic injury.

An objective measurement of skills is difficult. Checklists are easy to use, but to evaluate clinical skills, studies suggest that GRS is a more dependable measure. ${ }^{27} 42-44$ Cut scores are often used to assess performance and the selection of a cut score risk to be biased by evaluators opinions. There are recommendations for how to decide cut scores or define adequate performance. ${ }^{45-47}$ However, a GRS for a prehospital REBOA procedure does not exist and cut scores to the OSAPRA score had to be determined without previous empirical data. A possible method to set the cut score is the Angoff method, ${ }^{48}$ in which a group of experts establishes the cut score based on a fictitious 'borderline' candidate. Experts present a description of a performance that they believe is on the borderline between competent and incompetent, and the cut score is set based on the score of this performance. Borderline cases can also be identified by that the raters record 'red flag' performances, using a global impression. The reasons to identify a red flag performance for interventional procedures are often significant breaches of sterility or performances leading to damage to important structures or organs. ${ }^{27}$ We believe that a combination of cut scores and an overall global impression on safety and competence can be used as foundation to deem adequate competency.

Practice in an interventional radiology lab can be difficult to perform in places that lack this service or where hospital or interdepartment regulations are strict. We 
propose that the REBOA procedure then may be learnt at specialised courses with a structured educational programme, for instance, like the one described here.

Applying high-fidelity simulation to an educational programme provides a powerful platform for evaluating technical skills as well as team work and communication. In addition to the actual training, we consider the debriefing sessions as important for the learning effect. The debriefers role in the debriefing session is important and difficult, and the learning effect of such a session is dependent of the skills and learning environment created by the debriefer. ${ }^{33}$ One of the investigators works at the Centre for Medical Simulation and is trained as a facilitator in debriefing sessions. The debriefers are known to the trainees. We believe that this contributed positively to create a non-hostile debriefing environment.

It must be recognised that REBOA placement will not always be successful. Therefore, a part of the training must be to abort the procedure if difficult or if it interferes with performance of standard CPR. There will also be operational circumstances such as cold weather or environmental hazard where REBOA should not be initiated. This study does not answer how REBOA can be achieved during real-life field operations. Moreover, the frequency of REBOA complications can be different in a prehospital setting and clinical studies are needed to observe if REBOA is feasible in a prehospital setting during CA and if complications associated with REBOA balance the potential benefit from REBOA. We also emphasise that the concept of REBOA during CA is in its infancy and several issues related to what is the better technique must be developed.

We recognise that this study has some limitations. First, it is a single-centre study, and only assessed seven physicians and three paramedics. Second, we included only anesthesiologists working in a P-EMS system with a homogenous set of skills and the results might therefore not be generalised to physicians from other specialties. However, the study is relevant to services such as in Scandinavia, where mainly anesthesiologists participates in the physician-manned P-EMS. Third, the simulation was done on mannequins, and although the high-fidelity simulation mimicked the prehospital setting, it may not translate directly to the real prehospital environment. Fourth, this is a scenario where all participants are prepared specifically for testing the REBOA procedure and where all participants knew the indications well. Finally, the objective assessment chart had to be developed for this study, meaning that it has yet to be validated.

Strengths of this study is that it is specifically designed for a team competent in the Seldinger technique, thereby relevant for the personnel who will perform REBOA in real-life settings. We evaluated both technical and communication skills, as well as team work. The OSAPRA scoring chart is constructed in a systematic manner, based on input from physicians with a wide range of expertise.

REBOA may be an important modality for out-of-hospital ACLS. This is supported by animal studies on physiology during CPR. However, it is not known if REBOA will give benefit on human ACLS. An answer to this question can only be given by a comparative study of REBOA plus standard care versus standard care alone. However, it is reasonable to develop and perform an educational programme and to test in-field feasibility of REBOA in the prehospital setting before initiating a comparative study. This clinical feasibility study is currently in progress.

\section{CONCLUSIONS}

This four-step approach to educate, train and implement the REBOA technique in a prehospital working team provides adequate competence in a simulated setting. This training is a first step before the start of a planned feasibility trial of REBOA for OHCA. We recommend the use of a systematic training programme and the OSAPRA score to guide and improve training. In a simulated prehospital setting, the teams used 8.5 min to establish a REBOA catheter. This indicates that the procedure does not add significant time to the resuscitation time prehospital. Based on the feedback from the participants and the observers, we conclude that the procedure does not interfere with the quality of the ACLS given simultaneously.

\section{Author affiliations}

${ }^{1}$ Department of emergency medicine and pre-hospital services, St. Olavs Hospital, Trondheim, Norway

${ }^{2}$ Departmentof research and development, Norwegian Air Ambulance Foundation, Oslo, Norway

${ }^{3}$ Department of circulation and medical imaging, NTNU, Trondheim, Norway ${ }^{4}$ Department of thoracic anesthesiology and intensive care medicine, St. Olavs Hospital, Trondheim, Norway

${ }^{5}$ Department of radiology and nuclear medicine, St. Olavs Hospital, Trondheim, Norway

${ }^{6}$ Department of mechanical and industrial engineering, NTNU, Trondheim, Norway ${ }^{7}$ Department of anesthesiology and intensive care medicine, St. Olavs Hospital, Trondheim, Norway

Acknowledgements The authors wish to thank the participants in this study. Contributors JRB and TL designed the study, interpreted and analysed the data. JRB drafted the manuscript and prepared the figures/tables. ES, AJK and PK contributed to the design of the study and revised the manuscript. TS, CK and MS contributed on developing the simulation mannequin. All authors read and approved the final manuscript.

Funding This study was funded by the Norwegian Air Ambulance Foundation and The Trondheim Prehospital Research Group. The funders had no part in the design or execution of this study, nor the collection or management of the data, or in the preparation, review and approval of the manuscript.

Competing interests One of the authors (ES) has stock ownership and a board position in Reboa Medical AS. The other authors declare that they have no competing interests.

Patient consent for publication Not required.

Ethics approval This study was approved by the Regional Committee for Medical and Health Research Ethics (reference 2017/2482/REKmidt).

Provenance and peer review Not commissioned; externally peer reviewed.

Data sharing statement The datasets used and/or analysed during the current study are available from the corresponding author on reasonable request.

Open access This is an open access article distributed in accordance with the Creative Commons Attribution Non Commercial (CC BY-NC 4.0) license, which permits others to distribute, remix, adapt, build upon this work non-commercially, and license their derivative works on different terms, provided the original work is 
properly cited, appropriate credit is given, any changes made indicated, and the use is non-commercial. See: http://creativecommons.org/licenses/by-nc/4.0/.

\section{REFERENCES}

1. Hasselqvist-Ax I, Riva G, Herlitz J, et al. Early cardiopulmonary resuscitation in out-of-hospital cardiac arrest. $N$ Engl $J$ Med 2015;372:2307-15.

2. Engdahl J, Holmberg M, Karlson BW, et al. The epidemiology of outof-hospital 'sudden' cardiac arrest. Resuscitation 2002;52:235-45.

3. Moriwaki Y, Tahara Y, Kosuge T, et al. Etiology of out-of-hospital cardiac arrest diagnosed via detailed examinations including perimortem computed tomography. J Emerg Trauma Shock 2013;6:87-94

4. Dragancea I, Rundgren M, Englund E, et al. The influence of induced hypothermia and delayed prognostication on the mode of death after cardiac arrest. Resuscitation 2013;84:337-42.

5. Hughes CW. Use of an intra-aortic balloon catheter tamponade for controlling intra-abdominal hemorrhage in man. Surgery 1954;36:65-8.

6. Daley J, Morrison JJ, Sather J, et al. The role of resuscitative endovascular balloon occlusion of the aorta (REBOA) as an adjunct to ACLS in non-traumatic cardiac arrest. Am J Emerg Med 2017;35:731-6.

7. Sesma J, Labandeira J, Sara MJ, et al. Effect of intra-aortic occlusion balloon in external thoracic compressions during CPR in pigs. Am J Emerg Med 2002;20:453-62.

8. Nozari A, Rubertsson S, Wiklund L. Improved cerebral blood supply and oxygenation by aortic balloon occlusion combined with intra-aortic vasopressin administration during experimental cardiopulmonary resuscitation. Acta Anaesthesiol Scand 2000;44:1209-19.

9. Nozari A, Rubertsson S, Wiklund L. Intra-aortic administration of epinephrine above an aortic balloon occlusion during experimental CPR does not further improve cerebral blood flow and oxygenation. Resuscitation 2000;44:119-27.

10. Gedeborg R, Rubertsson S, Wiklund L. Improved haemodynamics and restoration of spontaneous circulation with constant aortic occlusion during experimental cardiopulmonary resuscitation. Resuscitation 1999;40:171-80.

11. Rubertsson S, Bircher NG, Alexander H. Effects of intra-aortic balloon occlusion on hemodynamics during, and survival after cardiopulmonary resuscitation in dogs. Crit Care Med 1997;25:1003-9.

12. Barton C, Manning JE, Batson N. Effect of selective aortic arch perfusion on median frequency and peak amplitude of ventricular fibrillation in a canine model. Ann Emerg Med 1996;27:610-6.

13. Manning JE, Murphy CA, Hertz CM, et al. Selective aortic arch perfusion during cardiac arrest: a new resuscitation technique. Ann Emerg Med 1992;21:1058-65

14. Paradis NA, Rose MI, Gawryl MS. Selective aortic perfusion and oxygenation: an effective adjunct to external chest compressionbased cardiopulmonary resuscitation. J Am Coll Cardiol 1994;23:497-504.

15. Nozari A, Rubertsson S, Gedeborg R, et al. Maximisation of cerebral blood flow during experimental cardiopulmonary resuscitation does not ameliorate post-resuscitation hypoperfusion. Resuscitation 1999;40:27-35.

16. Spence PA, Lust RM, Chitwood WR, et al. Transfemoral balloon aortic occlusion during open cardiopulmonary resuscitation improves myocardial and cerebral blood flow. J Surg Res 1990;49:217-21.

17. Suzuki A, Taki K, Kamiya K, et al. Cerebral blood flow during openchest cardiac massage with occlusion of the descending aorta in dogs. Resuscitation 1985;13:69-75.

18. Gedeborg R, Silander HC, Rubertsson S, et al. Cerebral ischaemia in experimental cardiopulmonary resuscitation--comparison of epinephrine and aortic occlusion. Resuscitation 2001;50:319-29.

19. Aslanger E, Golcuk E, Oflaz H, et al. Intraaortic balloon occlusion during refractory cardiac arrest. A case report. Resuscitation 2009;80:281-3.

20. Deakin CD, Barron DJ. Haemodynamic effects of descending aortic occlusion during cardiopulmonary resuscitation. Resuscitation 1996;33:49-52.

21. McGreevy D, Dogan E, Toivola A, et al. Endovascular resuscitation with aortic balloon occlusion in non-trauma cases: First use of ERREBOA in Europe. Journal of Endovascular Resuscitation and Trauma Management 2017;1:42.

22. Søvik E, Stokkeland P, Storm BS, et al. The use of aortic occlusion balloon catheter without fluoroscopy for life-threatening post-partum haemorrhage. Acta Anaesthesiol Scand 2012;56:388-93.
23. Foerster CR, Turgulov A. Prehospital endovascular occlusion of the aorta is now a technically feasible strategy for improving haemodynamics in CPR. Resuscitation 2015;93:e25.

24. Krüger AJ, Skogvoll E, Castrén M, et al. Scandinavian pre-hospital physician-manned Emergency Medical Services--same concept across borders? Resuscitation 2010;81:427-33.

25. Stannard A, Eliason JL, Rasmussen TE. Resuscitative endovascular balloon occlusion of the aorta (REBOA) as an adjunct for hemorrhagic shock. J Trauma 2011;71:1869-72.

26. Romagnoli AN, Teeter W, Wasicek $\mathrm{P}$, et al. No wire? No problem: Resuscitative endovascular balloon occlusion of the aorta can be performed effectively and more rapidly with a wire-free device. $J$ Trauma Acute Care Surg 2018;85:894-8.

27. Walzak A, Bacchus M, Schaefer JP, et al. Diagnosing technical competence in six bedside procedures: comparing checklists and a global rating scale in the assessment of resident performance. Acad Med 2015;90:1100-8.

28. Lendrum RA, Perkins ZB, Davies GE. A training package for zone III Resuscitative Endovascular Balloon Occlusion of the Aorta (REBOA). Scand J Trauma Resusc Emerg Med 2014;22(S1):P18.

29. Dawe SR, Pena GN, Windsor JA, et al. Systematic review of skills transfer after surgical simulation-based training. Br J Surg 2014;101:1063-76.

30. Norwegian Resuscitation Council. Norsk Resuscitasjonsråd. Norsk Resuscitasjonsråd. http://nrr.org/no/ (Accessed 9 Sep 2017).

31. Reznick R, Regehr G, MacRae H, et al. Testing technical skill via an innovative "bench station" examination. Am J Surg 1997;173:226-30.

32. Hseino H, Nugent E, Lee MJ, et al. Skills transfer after proficiencybased simulation training in superficial femoral artery angioplasty. Simul Healthc 2012;7:274-81.

33. Palaganas JC, Fey M, Simon R. Structured debriefing in simulationbased education. AACN Adv Crit Care 2016;27:78-85

34. Puślecki M, Ligowski M, Dabrowski M, et al. Development of regional extracorporeal life support system: The importance of innovative simulation training. Am J Emerg Med 2019;37:19-26.

35. Hilty WM, Hudson PA, Levitt MA, et al. Real-time ultrasound-guided femoral vein catheterization during cardiopulmonary resuscitation. Ann Emerg Med 1997;29:331-7.

36. Sobolev M, Slovut DP, Lee Chang A, et al. Ultrasound-guided catheterization of the femoral artery: a systematic review and meta-analysis of randomized controlled trials. J Invasive Cardiol 2015;27:318-23.

37. Okada $\mathrm{Y}$, Narumiya $\mathrm{H}$, Ishi $\mathrm{W}$, et al. Anatomical landmarks for safely implementing resuscitative balloon occlusion of the aorta (REBOA) in zone 1 without fluoroscopy. Scand J Trauma Resusc Emerg Med 2017;25:63.

38. Linnebur M, Inaba K, Haltmeier T, et al. Emergent non-image-guided resuscitative endovascular balloon occlusion of the aorta (REBOA) catheter placement: A cadaver-based study. J Trauma Acute Care Surg 2016;81:453-7.

39. MacTaggart JN, Poulson WE, Akhter M, et al. Morphometric roadmaps to improve accurate device delivery for fluoroscopy-free resuscitative endovascular balloon occlusion of the aorta. J Trauma Acute Care Surg 2016;80:941-6.

40. McComb BL, Munden RF, Duan F, et al. Normative reference values of thoracic aortic diameter in American College of Radiology Imaging Network (ACRIN 6654) arm of National Lung Screening Trial. Clin Imaging 2016;40:936-43.

41. Rogers IS, Massaro JM, Truong QA, et al. Distribution, determinants, and normal reference values of thoracic and abdominal aortic diameters by computed tomography (from the Framingham Heart Study). Am J Cardiol 2013;111:1510-6.

42. Hodges $\mathrm{B}$, Mcllroy $\mathrm{JH}$. Analytic global OSCE ratings are sensitive to level of training. Med Educ 2003;37:1012-6.

43. Regehr G, MacRae H, Reznick RK, et al. Comparing the psychometric properties of checklists and global rating scales for assessing performance on an OSCE-format examination. Acad Med 1998;73:993-7.

44. Hodges B, Regehr G, McNaughton N, et al. OSCE checklists do not capture increasing levels of expertise. Academic Medicine 1999;74:1129-34.

45. Shepard L. Standard setting issues and methods. Appl Psychol Meas 1980;4:447-67.

46. Kaufman DM, Mann KV, Muijtjens AM, et al. A comparison of standard-setting procedures for an OSCE in undergraduate medical education. Acad Med 2000;75:267-71.

47. Livingston S, Zieky M, Fowles M. Manual for setting standards on the basic skills assessment tests. Educ Test Serv 1978 https://www.ets. org/Media/Research/pdf/passing_scores.pdf

48. Ricker K. Setting cut-scores: a critical review of the angoff and modified angoff methods. Alta J Educ Res 2006;52:53-64. 